\title{
Plant-Herbivore Interactions: A Case of an Extreme Generalist, the Two-Spotted Spider Mite Tetranychus urticae
}

\author{
Cristina Rioja, ${ }^{1}$ Vladimir Zhurov, ${ }^{1}$ Kristie Bruinsma, ${ }^{1}$ Miodrag Grbic, ${ }^{1,2,+}$ and Vojislava Grbic ${ }^{1, \dagger}$ \\ ${ }^{1}$ Department of Biology, The University of Western Ontario, London, ON, N6A5B7, Canada; and ${ }^{2}$ University of La Rioja, \\ Logrono, 26006, Spain
}

Accepted 29 August 2017.

Plant-herbivore interactions evolved over long periods of time, resulting in an elaborate arms race between interacting species. While specialist herbivores evolved specific strategies to cope with the defenses of a limited number of hosts, our understanding of how generalist herbivores deal with the defenses of a plethora of diverse host plants is largely unknown. Understanding the interaction between a plant host and a generalist herbivore requires an understanding of the plant's mechanisms aimed at defending itself and the herbivore's mechanisms intended to counteract diverse defenses. In this review, we use the two-spotted spider mite (TSSM), Tetranychus urticae (Koch) as an example of a generalist herbivore, as this chelicerate pest has a staggering number of plant hosts. We first establish that the ability of TSSM to adapt to marginal hosts underlies its polyphagy and agricultural pest status. We then highlight our understanding of direct plant defenses against spider mite herbivory and review recent advances in uncovering mechanisms of spider mite adaptations to them. Finally, we discuss the adaptation process itself, as it allows TSSM to overcome initially effective plant defenses. A highquality genome sequence and developing genetic tools, coupled with an ease of mite experimental selection to new hosts, make TSSM an outstanding system to study the evolution of host range, mechanisms of pest xenobiotic resistance and plant-herbivore interactions. In addition, knowledge of plant defense mechanisms that affect mite fitness are of practical importance, as it can lead to development of new control strategies against this important agricultural pest. In parallel, understanding mechanisms of mite counter adaptations to these defenses is required to maintain the efficacy of these control strategies in agricultural practices.

The interactions between herbivores and their plant hosts result from an elaborate evolutionary interplay. For millions of years, plants have developed strategies to deter attackers and reduce pest fitness as a defense against herbivory, while herbivores have evolved mechanisms to overcome plant defenses. Plant defenses

Cristina Rioja and Vladimir Zhurov contributed equally.

Current address for Cristina Rioja: DynaMo Center, Department of Plant and Environmental Sciences, University of Copenhagen, Thorvaldsensvej 40, 1871 Frederiksberg C, Denmark

${ }^{\dagger}$ Corresponding authors: Miodrag Grbic; E-mail: mgrbic@uwo.ca and Vojislava Grbic; E-mail: vgrbic@uwo.ca

(c) 2017 The American Phytopathological Society are versatile and efficiently deter herbivory of most arthropod species. The interaction between a plant and a herbivore is defined as incompatible when plant constitutive defenses prevent pest attack or attack occurs but the plant recognizes the pest or its effectors and induces defenses. This leads to plant resistance and the plant is defined as a nonhost plant. In contrast, a compatible interaction occurs when the pest is either not detected by the plant or the pest is detected but has evolved the ability to avoid or overcome plant defenses. Under these circumstances, plant defenses are ineffective and the pest can successfully develop and reproduce. Such interaction leads to plant susceptibility and the plant is considered a suitable host for the particular herbivore, Figure 1A.

Herbivores can be classified, based on their host-range specialization, into specialists (feeding on one or a few plant species within the same genus), oligophagous herbivores (feeding on several plant species, typically belonging to the same family), and generalists (feeding on many hosts belonging to different plant families) (Barrett and Heil 2012; Bernays and Graham 1988; Futuyma and Gould 1979). On the generalist end of the spectrum is the chelicerate herbivorous pest Tetranychus urticae (Koch) or the two-spotted spider mite (TSSM), which feeds on over 1,100 plant species (including more than 150 crops) that belong to more than 140 different families (Migeon and Dorkeld 2010). Its wide host range, easy laboratory maintenance, short life cycle, and ability to feed on plant model species (e.g., Arabidopsis and tomato), combined with recently developed TSSM genomic and genetic tools (Grbic et al. 2011; Kwon et al. 2013; Suzuki et al. 2017a; Van Leeuwen et al. 2012), makes TSSM an excellent model for studies aimed at the identification of molecular mechanisms underlying the evolution of herbivore host range, plant-herbivore interactions, and mechanisms of pest xenobiotic resistance.

TSSM's capacity to feed on a wide range of hosts that utilize diverse defenses to fend off herbivory implies that TSSM has evolved an extraordinary ability to evade a great heterogeneity of defense traits associated with potential hosts. Congruent with TSSM's ability to overcome a range of plant defenses is the expansion of gene families that encode proteins implicated in the digestion, detoxification, and transport of xenobiotics (Grbic et al. 2011). Besides gene families that are conserved across arthropods, TSSM has also acquired new classes of the detoxification genes through horizontal gene transfers. For example, the TSSM genome harbors a family of intradiol ring cleavage dioxygenases that may enable them to metabolize aromatic compounds frequently found in phytochemicals (Grbic et al. 2011) and a cyanate lyase that allows mites to feed on cyanogenic plants (Wybouw et al. 2014). As members of these gene families are expressed 
in adult and immature developmental stages under various conditions and plant hosts (Grbic et al. 2011; Sterck et al. 2012), individual TSSM populations might be able to perform well across all potential hosts and realize the full complement of the species host range.

However, it has also been shown that individual TSSM populations do not perform equally well on all potential hosts (Fellous et al. 2014; Gotoh et al. 1993; Navajas 1999). An example of the differential performance of locally adapted populations is shown for TSSM field populations collected from citrus, oleander, and tomato (Fellous et al. 2014). In this particular case, tomato populations were able to develop only on tomato plants (of the three plant hosts tested). However, citrus populations performed well on both citrus and tomato but not on oleander, while oleander populations performed similarly well on all three hosts tested, indicating that local TSSM populations have different performances on different plant hosts and that adaptation to one host may simultaneously adapt them to some other hosts as well.
Even though individual TSSM populations may have a narrow spectra of hosts relative to the species-wide complement, experimental selection demonstrated that TSSM can adapt to novel hosts upon host shift (Agrawal 2000; Agrawal et al. 2002; Fry 1989; Magalhães et al. 2009; Wybouw et al. 2015). In these experiments, mites initially showed low preference or acceptability of the new plant hosts and had low performance on them, reflecting the efficiency of one or both the plant's constitutive and induced defenses to deter TSSM herbivory. However, over time (i.e., five to 25 generations), host acceptance and mite performance gradually improved (Fig. 1B). Experimental selection studies performed under controlled laboratory conditions that are void of complex ecological interactions (e.g., coexistence of plant species, competitors, and predators) can uncover the physiological basis of TSSM host adaptations that are based on TSSM's resistance to the originally effective plant defenses and exclude adaptation processes that depend on, for example, host-finding behavior or predator avoidance.
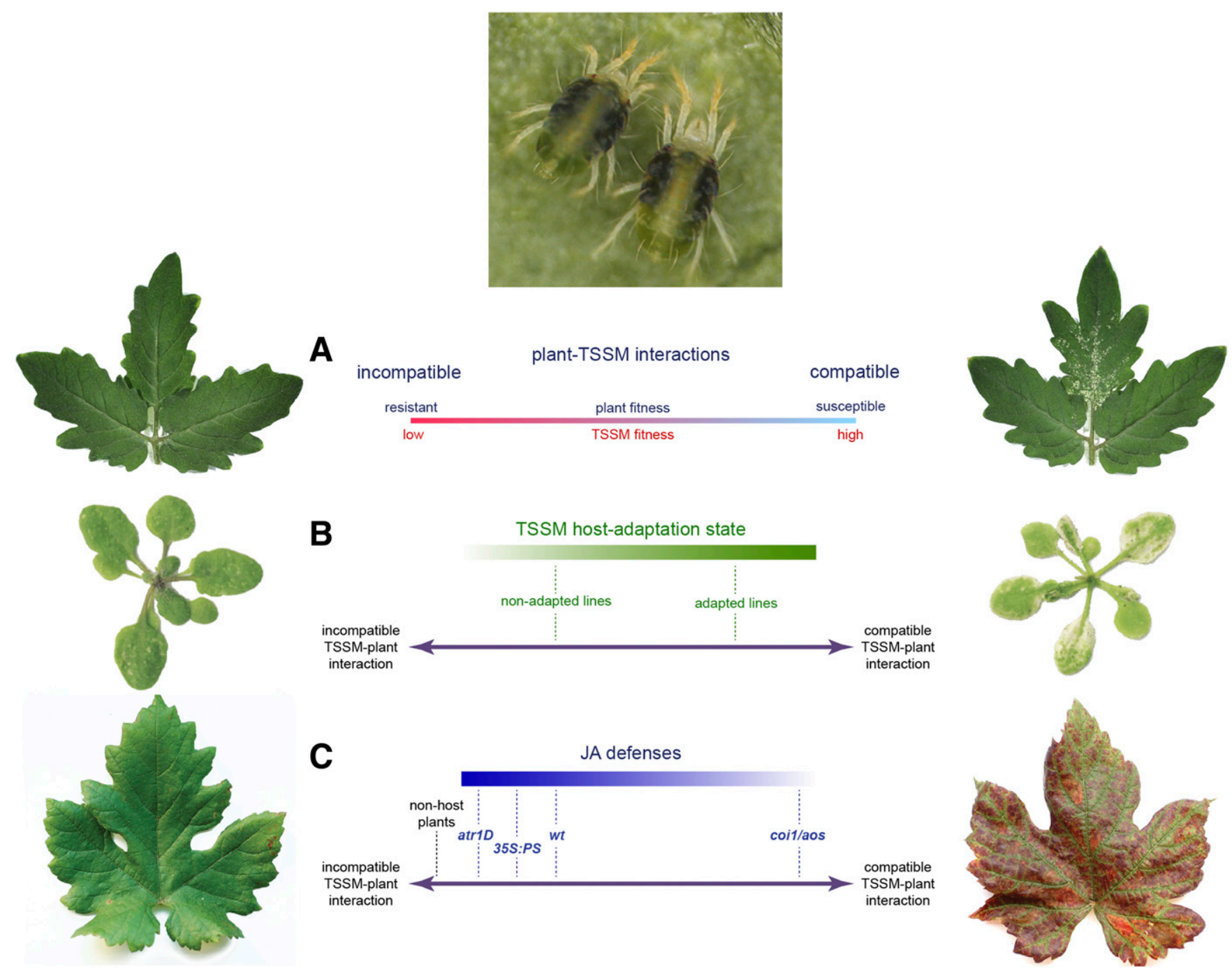

Fig. 1. Interactions between the two-spotted spider mite (Tetranychus urticae) (TSSM) and plant hosts (tomato, Arabidopsis, and grapevine). A, Plant-T. urticae interactions are described by the continuum in the compatibility that ranges from the incompatible interactions, characterized by plant resistance and low TSSM fitness, to compatible interactions, characterized by plant susceptibility and high TSSM fitness. Plant damage resulting from the incompatible plant-T. urticae interactions is shown on the left and from the compatible interaction on the right. $\mathbf{B}$ and $\mathbf{C}$, Compatibility of plant-T. urticae interactions depends on the TSSM host-adaptation state and the ability of plants to mount the jasmonate defenses. B, Plants are resistant to host-nonadapted TSSM strains. Continuous exposure of TSSM to such a marginal host can lead to TSSM host adaptation. In such cases, TSSM populations gain the ability to use initially unfavorable hosts. Host-adapted mites have increased performance that is comparable to the performance of nonadapted mites on plants that lack jasmonic acid (JA) defenses. C, Defenseless plants that lack JA or its signaling (coil/aos) establish a compatible TSSM-plant interaction even with host-nonadapted mite strains. On the opposite end, plants with the constitutive JA signaling (35S:PS; tomato) and plants with the constitutive overexpression of defensive compounds regulated by JA (atr1D; Arabidopsis) show resistance to herbivory of most TSSM strains. At the extreme end of the incompatibility spectrum are nonhost plants that are resistant to all TSSM populations. The placement of lines on the compatibility axis in B and C is approximate; its positioning can slide toward either end of the axis in different TSSM strains and plant genotypes. 
One aspect of understanding TSSM's extreme polyphagy is an understanding of mechanisms underlying the adaptability of individual TSSM populations to novel plant hosts. In addition, as only host-adapted TSSM populations cause substantial damage that significantly and negatively affects the fitness of their respective hosts (Fig. 1), adaptability is also the basis of TSSM's agricultural pest status. In this review, we highlight and discuss our current understanding of the molecular physiology of TSSM-plant interactions that underlie different stages in TSSM host adaptation process. Since mites adapt to plant defenses that initially restrict their performance, we first review our current knowledge of plant defenses aimed to deter TSSM herbivory. Then, since TSSM populations gain the ability to overcome these plant defenses, in the second part of this review, we discuss strategies evolved in mites to bypass plant defenses. Finally, we discuss potential molecular mechanisms of the adaptation process itself, as they ultimately underlie the mite's ability to feed on many host plants.

\section{PLANT DEFENSES AGAINST SPIDER MITE HERBIVORY}

To understand TSSM adaptation to its plant hosts, it is important to identify factors that initially restrict fitness of host-nonadapted TSSM populations. Here, we review direct plant defenses against the TSSM, as they are major contributors to the incompatibility observed between nonadapted TSSM populations and their potential hosts under both field and laboratory conditions.

Constitutive defenses, including both physical and chemical barriers, are potent deterrents of TSSM herbivory. TSSM feed from the cell content of individual mesophyll cells and use cheliceral stylets to reach them. During feeding, stylets transverse the leaf epidermis without damaging it, either in between epidermal pavement cells (Fig. 2A) or through stomatal openings (Fig. 2B) (Bensoussan et al. 2016)). Thick cuticle or wax depositions on the leaf surface of some of the plant hosts are physical barriers that impede the ability of mites to penetrate their stylets past the epidermis and into the leaf mesophyll (Fig. 2A). In such cases, mites may exclusively depend on stomatal openings to reach the inner leaf cellular layers with their stylets, as shown for some Tetranychidae and Tenuipalpidae mites (Beard et al. 2012; Marriott et al. 2013). However, additional deposits at and around stomatal openings, e.g., in dwarf palmetto Sabal minor (Jacq.), prevent mite feeding, rendering such plants nonhosts (Beard et al. 2012). Apart from physical barriers, plant metabolites that are either toxic, repellent, or both to TSSM can also confer high levels of constitutive resistance. Acylsugars (Resende et al. 2002; Salinas et al. 2013), methyl ketones (Antonious et al. 2014; Chatzivasileiadis and Sabelis 1997), and terpenoids (Bleeker et al. 2012) that accumulate in trichomes of wild tomato relatives contribute to their resistance against TSSM. These metabolites have either been lost (Bleeker et al. 2012), are present at lower levels (Williams et al. 1980), or have a narrower range (Ghosh et al. 2014) in domesticated tomato. Thus, current breeding efforts focus on the restoration of their biosynthesis in elite tomato genotypes (Bleeker et al. 2012; Fan et al. 2016). In addition, phenolic compounds, e.g., in chrysanthemum (Kielkiewicz and van de Vrie 1990; Kos et al. 2014), terpenoids, e.g., in cucumber and citrus (Agut et al. 2015; Balkema-Boomstra et al. 2003), and flavonoids, e.g., in citrus (Agut et al. 2014) correlate with cultivar resistance to TSSM. Constitutive defenses may render plants nonacceptable. In such cases, TSSM readily disperse in search of more favorable hosts without causing damage on the resistant plant host (Diaz-Riquelme et al. 2016).

If constitutive defenses fail to deter TSSM, they start to feed. However, mite feeding induces plant responses that can negatively impact TSSM performance, leading to plant resistance. These responses are triggered by the recognition of molecules that are either characteristic of the herbivore (herbivore associated molecular patterns [HAMPs] [Mithofer and Boland 2008]) or plant damage that is associated with herbivore feeding (damage associated molecular patterns [DAMPs] [Boller and Felix 2009]). At present, the elicitors of plant responses to TSSM herbivory are not known. However, mites have a unique feeding pattern that differentiates them from other cell content-feeding arthropods, such as thrips, or phloem feeders, e.g., aphids. While thrips use mandibles for leaf penetration and stylets to subsequently suck the released cell content (Abe et al. 2008; Kindt et al. 2003; Walling 2000), mites and phloem feeders (e.g., aphids and white flies) insert stylets directly into individual cells they feed from. However, phloem feeders feed for prolonged periods of time from cells that remain alive (Walling 2008), while mites empty the content of the cell they feed on within 10 to 30 min (Fig. 2B and C) (Bensoussan et al. 2016). As cells that mites feed from die, most likely the surrounding cells generate the response to the HAMPs and DAMPs released during TSSM feeding (Fig. 2C). It is hypothesized that cellular content ingested by mites undergoes preoral digestion and liquefaction, potentially generating breakdown products of plant compounds that can act as elicitors, as shown for proteolytic products of the plant chloroplastic ATP synthase $\gamma$-subunit found in Spodoptera frugiperda (fall armyworm) oral secretions (Schmelz et al. 2006). In addition, TSSM feeding causes a fragmentation of cellular membranes that allows leakage of cytoplasmic content into the apoplast (Tanigoshi and Davis 1978). Apart from potential elicitors deposited at the feeding site, TSSM excrete enzymatically active feces and synthesize and deposit silk on the leaf surface (Fig. 2D) (Santamaría et al. 2015), both of which might be a rich source of potential elicitors. Furthermore, TSSM salivary secretions could contribute additional elicitors of plant responses (Jonckheere et al. 2016; Villarroel et al. 2016).

The receptors for TSSM-associated HAMPs and DAMPs have not yet been identified. Intriguingly, homologs of LYSMCONTAINING RECEPTOR-LIKE KINASE 4 (LYK4), shown to be involved in chitin-triggered signaling in Arabidopsis (Wan et al. 2012), are induced by TSSM herbivory across plant species (Diaz-Riquelme et al. 2016), leading to the hypothesis that chitin present in the arthropod exoskeleton may be one of the elicitors of plant defense responses. Transduction of TSSMtriggered signaling in plant tissues is largely unknown as well. However, it appears to be shared with other biotic stressors. For example, Arabidopsis Ser/Thr phosphatase of type 2C (AP2C1) and Mite Attack Triggered Immunity (MATI) are regulators that affect plant responses not only induced by TSSM but also by the necrotrophic pathogen Botrytis cinerea and the chewing lepidopteran Spodoptera exigua, respectively (Santamaría et al. 2017a; Schweighofer et al. 2007). Besides locally induced plant responses that occur at the feeding site, the perception of TSSM feeding is also transmitted to distal plant tissues to trigger systemic responses that prepare undamaged tissues against a secondary TSSM attack. It was recently shown that glutamic acid and other means of communication between roots and shoot are important for the establishment of systemic defense against TSSM in citrus (Agut et al. 2016). In addition, it has been demonstrated that $T$. urticaeinduced volatiles can induce resistance in neighboring plants, accounting for plant to plant induction of citrus defenses against mite herbivory (Agut et al. 2015).

Jasmonic acid (JA) is a principal and conserved regulator of induced plant defenses triggered by a wide array of herbivores, such as thrips (Abe et al. 2008, 2009; Li et al. 2002), aphids (Ellis et al. 2002; Koramutla et al. 2014), whiteflies (Zarate et al. 2007; Zhang et al. 2009), caterpillars (Yang et al. 2015; Zheng et al. 2007), and spider mites (Ament et al. 2004; Li et al. 2002, 2004a; Schweighofer et al. 2007; Zhurov et al. 2014). JA levels tightly correlate with the degree of plant resistance to TSSM herbivory, such that plants with constitutive JA-mediated responses 
(e.g., the Arabidopsis atr1D mutant that overaccumulates indole glucosinolates [Bender and Fink 1998] or tomato 35S:PS transgenic plants that overaccumulate the prosystemin gene product and exhibit a constitutively activated JA signaling pathway [Chen et al. 2006; Kandoth et al. 2007]) are more resistant to bean-maintained TSSM populations, relative to their corresponding wild-type plants (Fig. 1C) (Li et al. 2002; Zhurov et al. 2014). Conversely, plants that lack the ability to synthesize JA or to transmit JA-signaling (e.g., aos/coil/def-1) are susceptible to these mite populations (Fig. 1C) (Ament et al. 2004; Howe et al. 1996; Li et al. 2004a; Park et al. 2002). JA was shown to interact with other plant hormones to regulate plant defenses. These interactions allow diversification of plant-induced defenses and their integration with other stresses and developmental cues. In particular, salicylic acid (SA), ethylene, and abscisic acid have been shown to modulate JA-induced defenses in response to herbivory (Erb et al. 2012; Verhage et al. 2011; Vos et al. 2013).
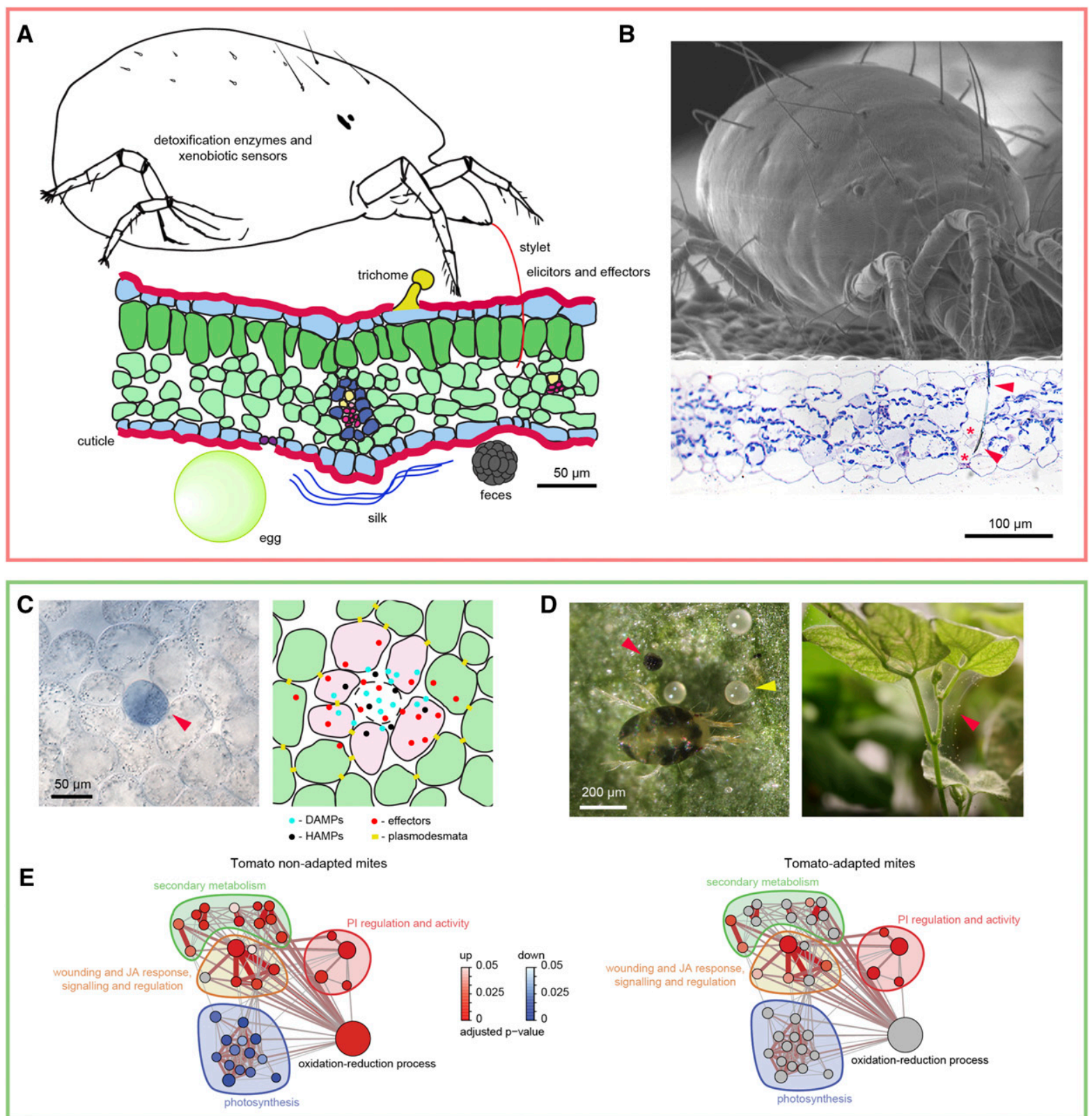

$\mathbf{F}$

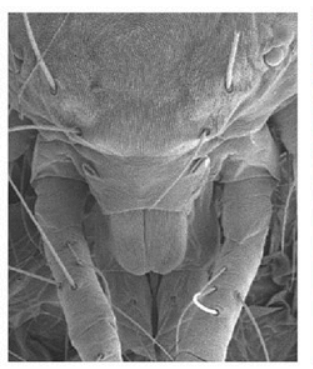

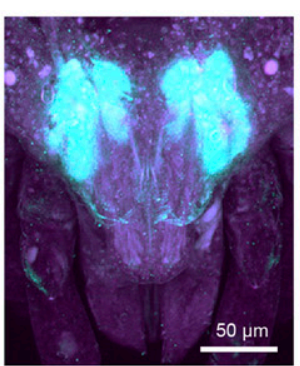


SA- and JA-mediated responses are antagonistic in many plantherbivore interactions. In particular, phloem feeders induce the SA-responses that, in turn, suppress the effective JA-regulated plant defenses (Walling 2008), aphids (Coppola et al. 2013; De Vos et al. 2005; Giordanengo et al. 2010), and whitefly (Kempema et al. 2007; Zarate et al. 2007). However, even during an incompatible interaction with its host, TSSM induces the accumulation of both JA and SA in tomato (Alba et al. 2015; Ament et al. 2004, 2010; Glas et al. 2014; Kant et al. 2004, 2008; Martel et al. 2015), Arabidopsis (Zhurov et al. 2014), and citrus (Agut et al. 2014). In this context, SA does not antagonize JA responses. Rather, SA responses contribute to defenses against TSSM in tomato (Alba et al. 2015; Ament et al. 2004) but not significantly in Arabidopsis (Zhurov et al. 2014) or citrus (Agut et al. 2014). Interestingly, the antagonism between SA- and JAsignaling pathways has been implicated in the regulation of indirect plant defenses against TSSM in bean (Wei et al. 2014), indicating that the interaction between these hormones is plant species-dependent and can differentially affect different responses.

The differential contribution of plant hormones to the induction of plant defenses in different plant hosts parallels the remarkable plant-host specificity of defense compounds. For example, Arabidopsis, tomato, and grapevine responses to feeding of the TSSM reference "London" strain shared only 36 one-to-one orthologous genes (Diaz-Riquelme et al. 2016). Arabidopsis defenses rely mostly on indole glucosinolates (IGs), secondary metabolites whose levels increase upon TSSM herbivory (Zhurov et al. 2014), due to the induced expression of their biosynthetic genes regulated by JA (Brader et al. 2001). On the other hand, TSSM feeding induces the expression of phenylpropanoid, flavonoid, and terpenoid biosynthetic genes, as well as a wide range of antinutritive enzymes (e.g., proteinase inhibitors $[P I]$, amino acid catabolizing enzymes, polyphenol oxidases) in tomato (Kant et al. 2004; Martel et al. 2015). Even though the PI gene families are present in both tomato and Arabidopsis, PI genes are recruited for defense in tomato but not in Arabidopsis. PI genes induced by TSSM feeding belong to tomatospecific members within the $P I$ expanded family that have acquired transcriptional regulation by JA. Conversely, PI family members with clear orthology between tomato and Arabidopsis were not regulated by JA and were not induced by TSSM feeding (Martel et al. 2015). Thus, expansion within a family of plant proteins and acquisition of the regulation of their expression by JA, contributed to the establishment of host-specific induced responses to herbivory.

In most cases, host defense compounds that restrict mite herbivory are unknown. At present, it is not clear if PI and other antinutritive enzymes contribute to tomato resistance to TSSM. For example, leucine aminopeptidase (Gu et al. 1999), threonine deaminase (Chen et al. 2007), and arginase (Chen et al. 2004) were shown to function only in an alkaline $\mathrm{pH}$ range (characteristic of lepidopteran midgut), with little or no activity at $\mathrm{pH}$ values below 6.0. As such, they are ineffective against pests with the acidic guts, e.g., the Colorado potato beetle (Felton et al. 1992; Gonzales-Vigil et al. 2011) and probably T. urticae (Carrillo et al. 2011; Erban and Hubert 2010). Likewise, specific plant metabolites that are toxic to TSSM are known only for a limited number of hosts. Among these are cucurbitacin-c from cucumber (Agrawal 2000; Da Costa and Jones 1971), $O$-dimethylallyleugenol from Japanese star anise (Illicium anisatum) (Koeduka et al. 2014), 7-epizingiberene from S. habrochaites (Bleeker et al. 2012), synthetic and natural acyl sugars (Puterka et al. 2003), methyl ketones (2-tridecanone and 2-undecanone) from (wild) tomato (Chatzivasileiadis and Sabelis 1997), and indole glucosinolates from Arabidopsis (Zhurov et al. 2014). Even when such phytochemicals have been identified, their TSSM targets remain elusive. The identification of defense compounds with acaricidal activity requires functional analysis of individual candidate host defense metabolites and proteins. Recognition of their targets and determination of their mode of action as well as their potential modifications in TSSM gut upon ingestion will greatly facilitate the understanding of mechanisms of plant resistance as well as mechanisms used by the host-adapted TSSM populations to render them inefficient.

\section{TSSM COUNTER-ADAPTATIONS TO PLANT DEFENSES}

The improved reproductive performance of TSSM on initially incompatible hosts indicates that host-adapted mites are able to overcome plant defenses. Several mechanisms can lead to increased herbivore performance on a particular plant host, of which manipulation of host induced responses and biochemical adaptations or detoxification have been described for TSSM.

\section{Manipulation of host defense physiology.}

In certain cases of compatible TSSM-plant interactions, plant responses can be profoundly affected by the herbivore. For example, tomato-adapted TSSM populations (Alba et al. 2015; Kant et al. 2008; Wybouw et al. 2015; Xémenez-Embún et al. 2017) and mites specialized on Solanaceous crops (Tetranychus evansi [Baker \& Pritchard] [Sarmento et al. 2011; Alba et al. 2015] and Aculops lycopersici [Massee] [Glas et al. 2014])

\footnotetext{
Fig. 2. Cellular and molecular aspects of plant-Tetranychus urticae interactions. A, Summary schematics depicting potential determinants of plant-T. urticae interactions. The two-spotted spider mite (TSSM) feeds from the content of leaf mesophyll cells (dark green: palisade mesophyll; light green: spongy mesophyll). Stylet (red thin line) crosses the epidermal leaf layer (in light blue) either in between the pavement cells (as shown) or through the stomatal opening (stomatal guard cells are shown in the lower epidermis as two pink cells below which the cuticule [red line] is disrupted). The TSSM delivers potential elicitors and effectors into the plant tissue via the stylet. Egg oviposition fluid, silk, and feces might be additional sources of TSSM elicitors and effectors. Plants use constitutive defenses, physical barriers (cuticle), and phytochemicals (frequently deposited in trichomes [shown in yellow]), to fend TSSM herbivory. In addition, mite feeding elicits plant-induced responses that may result in the synthesis of defense compounds that are either toxic to mites or decrease the mite's ability to utilize plant nutrients. The TSSM uses various classes of proteins (e.g., effectors and detoxification enzymes) to decrease the efficiency of plant defense compounds. B, Composite of the scanning electron microscopy (SEM) image of spider mite feeding on a bean leaf and cross-section of a leaf, capturing feeding site with damaged and consumed cells (red asterisk) and part of the spider mite stylet (red arrowhead). The stylet penetrated the leaf epidermis through the stomatal opening. C, Bright field optical section of trypan blue-stained leaf after spider mite feeding (left panel). Spider mite feeding results in a death of the single mesophyll cell, which stains blue in these preparations (red arrowhead). The content of the feeding cell is removed, also seen in the labeled cells in B. The right panel shows a schematic of the spider mite feeding site. The cell TSSM fed on is shown in white, with fragmented plasma membrane. Expected damage- and herbivore-associated molecular patterns (DAMPs and HAMPs) are shown as blue and black dots, respectively, while putative TSSM effectors are shown in red. These molecules are expected within the damaged feeding cell and in the apoplast surrounding it, in which they may diffuse. Cells that directly respond to these DAMPs and HAMPs trigger local responses and are shown in pink. Cells surrounding the feeding site and not directly exposed to DAMPs and HAMPs (light green) mount the systemic response. The model predicts that some TSSM effectors (red dots) are internalized by cells surrounding the cell TSSM fed on. These effectors may modulate plant transcriptional response to TSSM feeding. D, Potential TSSM-HAMPs. Enzymatically active feces (red arrowhead), developing eggs (yellow arrowhead) on the surface of the leaf (on the left panel), and extensive silk deposits (red arrowhead) of TSSM-infested bean plant (on the right panel). E, Gene set enrichment analysis shows that a tomato-adapted TSSM population is capable of attenuating transcriptome-wide plant responses that are detectable in plants subjected to herbivory by nonadapted spider mite population. F, SEM image of mouth parts and frontal part of spider mite prosoma (left), next to the confocal image showing the expression of putative secreted protein in the salivary gland of a spider mite (cyan) and autofluorescence of spider mite cuticle (magenta) (right). Putative secreted protein may act as an effector or an elicitor that is deposited by TSSM at the feeding site. G, Expansion of xenobiotic sensing receptors gene family and gene families involved in digestion, detoxification, and molecular transport in TSSM genome. Gene number ratio shown is relative to Drosophila melanogaster (TSSM: Drosophila).
} 
can attenuate plant-induced responses relative to those induced by the nonadapted mites. An example of such attenuated tomatoinduced response to feeding of tomato-adapted TSSM populations is shown in Figure 2E (Wybouw et al. 2015). Even though these attenuated responses were associated with plant susceptibility, their direct contribution to the TSSM adaptive state has not yet been functionally demonstrated.

TSSM (Jonckheere et al. 2016; Villarroel et al. 2016), like other herbivores (Felton et al. 2014; Hogenhout and Bos 2011; Kaloshian and Walling 2016), phloem-feeders (Bos et al. 2010; Elzinga et al. 2014; Furch et al. 2015; Will et al. 2013), lepidopteran herbivores (Consales et al. 2012; Dafoe et al. 2013 Schmelz et al. 2012; Wu et al. 2012), and hessian fly (Williams et al. 2011; Zhao et al. 2015), are able to secrete molecules that affect their interaction with host plants. In silico predictions, analysis of prosoma-enriched transcripts and peptidomic analysis of compounds secreted into an artificial diet led to a systematic analysis of the TSSM secretome (Jonckheere et al. 2016; Villarroel et al. 2016). TSSM secreted proteins are produced in TSSM secretory glands (Fig. 2F) (Jonckheere et al. 2016; Villarroel et al. 2016) and are presumably deposited to the plant tissue via the stylet during feeding. The ectopic expression of a few of the identified TSSM and T. evansi proteins in Nicotiana benthamiana resulted in the suppression of SA- and JA-regulated defenses and increased mite performance, consistent with the possibility that some of these candidate proteins act as effectors (Schimmel et al. 2017; Villarroel et al. 2016). Deciphering the biochemical activities of TSSM secreted proteins will be critical for the understanding of mechanisms of TSSM host adaptation. Future research should aim at addressing the following questions: What are the host targets of TSSM effectors? Where are they localized (given that TSSM kills the cell it feeds from)? What is the function of host targets in the establishment of plant defenses? Are host targets conserved across TSSM plant hosts? How do TSSM secreted proteins reprogram host defenses?

Besides herbivore-encoded secreted proteins, proteins originating from herbivore-associated microbes have also been identified in the blend of molecules responsible for modulating plant responses (Chaudhary et al. 2014; Chung et al. 2013a and b; Elzinga and Jander 2013; Guo et al. 2013; Ray et al. 2016). Bacterial species from genera Wolbachia, Cardinium, Spiroplasma, and Rickettsia are commonly associated with the TSSM. They affect mite reproductive development (Breeuwer 1997; Enigl and Schausberger 2007; Gotoh et al. 2003, 2007; Weinert et al. 2009), but their ability to modulate plant-induced responses and mite performance has been only recently postulated (Staudacher et al. 2017). In addition, some mite species, e.g., false spider mites of the genus Brevipalpus (Acari), transmit viruses that attenuate mite-induced plant defenses, resulting in increased mite performance and greater virus transmissibility (Arena et al. 2016). While the current focus of the search for TSSM effectors lies in the analysis of oral secretions, TSSM excrete enzymatically active feces (Santamaría et al. 2015 ) that could be an additional source of elicitors or effectors, as demonstrated in the fall armyworm (Ray et al. 2015, 2016).

\section{Detoxification of plant defense compounds and metabolic resistance.}

In addition to manipulating levels of defense compounds in planta, herbivores overcome plant compound toxicity through excretion, sequestration, or detoxification, singly or in combination, as well as target-site mutations, through processes termed 'metabolic resistance.' While excretion, sequestration, and targetsite mutation were shown to underlie host adaptation in specialist herbivore populations (Dobler et al. 2012; Pentzold et al. 2014, 2015), detoxification of plant metabolites has been proposed to be the prevailing mechanism of host adaptation in generalist herbivores (Heidel-Fischer and Vogel 2015; Li et al. 2000; Wybouw et al. 2014). Carboxyl/cholinesterases, cytochrome P450 monooxygenases (P450s), glutathione- $S$-transferases, and UDPglycosyltransferases (UGTs) are expected to be the major enzymes contributing to the detoxification of plant defense compounds. Analysis of the TSSM genome revealed lineage-specific expansions in all gene families encoding enzymes involved in xenobiotic detoxification (Fig. 2G) (Grbic et al. 2011), however, their direct involvement in TSSM host adaptation awaits functional analysis.

In general, metabolic resistance can result from two main mechanisms: i) the overexpression of genes encoding enzymes that can metabolize (modify, degrade, or detoxify) plant toxins, and ii) allelic variation in the gene-coding region of the detoxification enzymes that generate allozymes with increased metabolic efficiency. Neither of these two mechanisms have been demonstrated in TSSM host adaptation. However, in the adaptation of the polyphagous aphid Myzus persicae (Myzus persicae nicotianae) to tobacco, it has been shown that a dinucleotide expansion within the promoter region and gene amplification (up to 50-fold increase in the copy number) leads to the overexpression of the cytochrome $\mathrm{P} 450$ CYP6CY3 to a level that efficiently detoxifies nicotine (Bass et al. 2013). Induced expression of detoxification genes upon host change has been well documented in TSSM (Grbic et al. 2011; Wybouw et al. 2015; Zhurov et al. 2014). In particular, analysis of the transcriptional response of TSSM to Arabidopsis and its associated IGs identified 40 genes with dose-dependent expression levels correlated with levels of IGs (Zhurov et al. 2014). Half of the IGresponsive genes encoded P450s and UGTs. Upregulation of these detoxification enzymes is consistent with the possibility that IGs are detoxified by the oxidation-conjugation reactions performed by P450s and glycosyltransferases, respectively. However, the ability of these enzymes to metabolize IGs is, at present, not known.

Besides their overexpression, an alteration in the primary sequence of detoxification genes is another mechanism that can lead to metabolic resistance and host adaptation by a herbivore. For example, Mao et al. (2007) showed the existence of an intraspecific sequence variation at the CYP6AB3 locus in the parsnip webworm (Depressaria pastinacella) that allowed the formation of local parsnip webworm populations that match the furanocoumarin content of their plant hosts. The structural, sequence, and copy number variation in genes involved in xenobiotic stress have not been assessed across different TSSM local populations. However, a high-quality TSSM genome sequence and its small size make sequence analysis of host-adapted TSSM populations feasible. Linking potential structural and allelic variations to host adaptation will then be possible through genetic crosses and subsequent experimental selection on different hosts. In cases in which one or more defense compounds may be known, a functional characterization of metabolic capabilities and substrate specificities of different allozymes would determine their contribution to host adaptation.

\section{The TSSM dilemma: manipulate host defenses or detoxify?}

The relative importance of the manipulation of host defense physiology and detoxification in TSSM-plant interactions has not been experimentally addressed. At present, it is unclear whether and how host chemistry affects the mechanism of TSSM adaptation. One could hypothesize that plant hosts with a single defense metabolite impose similar xenobiotic stress as pesticides, and thus, TSSM adaptation to such hosts might mirror mechanisms underlying pesticide resistance detoxification of a xenobiotic compound. Conversely, manipulation of host defenses that results in the attenuation of plant-induced responses may be more efficient in reducing the toxicity imposed by the proteinaceous defense compounds (e.g., antinutritive enzymes that have multiple or unspecific targets) or when multiple compounds act to restrict TSSM performance. While detoxification as 
a mechanism of adaptation can be efficient against both constitutive and induced plant defenses, host manipulation has, so far, only been described in the context of the induced plant responses.

Whether host-adapted TSSM populations use both mechanisms simultaneously to counteract plant defenses or they are mutually exclusive remains to be determined. Likewise, it is not clear if a TSSM population that uses one mechanism of host adaptation can switch to another upon host change. Elucidation of the significance of TSSM host-adaptation mechanisms necessitates simultaneous characterization of both manipulative and detoxifying capabilities of TSSM populations while feeding on plant hosts they are adapted to. However, such correlative analysis requires functional scrutiny of these two capabilities to establish their requirement for the TSSM adaptive evolution to a specific host.

\section{MECHANISMS OF ADAPTATION}

The ability of TSSM to establish populations on initially unfavorable hosts has been demonstrated in numerous ecological studies. However, with the advancement of genetic and genomic tools established for TSSM (Grbic et al. 2011; Kwon et al. 2015; Suzuki et al. 2017b; Van Leeuwen et al. 2012), it is now possible to investigate the molecular basis of TSSM adaptability to xenobiotics. Recently, major strides were accomplished in the understanding of TSSM resistance to pesticides (Van Leeuwen and Dermauw 2016). Prior knowledge of the pesticide active ingredient and, in most cases, its target greatly facilitated the identification of target-site changes (both point mutations and amplification) and detoxification enzymes that underlie or correlate with the evolution of TSSM pesticide resistance. Such studies are, so far, lacking for TSSM adaptation to plant xenobiotics. Hence, the extreme polyphagous feeding pattern of TSSM raises the following questions. Which properties of TSSM genome and biology predispose TSSM but not other herbivores to readily adapt to different plant hosts? Do TSSM populations have considerable genetic variability that allows the selection of host-resistant individuals, or do they have an extraordinary phenotypic plasticity that enables them to efficiently respond to plant xenobiotics?

Intraspecific variation that affects life-history traits and host utilization of mite populations has been described in both polyphagous (T. urticae [Diaz-Riquelme et al. 2016; Fellous et al. 2014; Kant et al. 2008; Xémenez-Embún et al. 2017], T. kanzawai [Ozawa et al. 2017], and T. pacificus [Scranton et al. 2013]) and oligophagous (T. evansi [Alba et al. 2015; Santamaría et al. $2017 \mathrm{~b}]$ ) mites. While, in most cases, the genetic differences between mite strains with different host utilization have not been determined, the difference between two genotypes in T. kanzawai has been attributed to a single gene (Yano et al. 2003) whose dominant allele associates with the higher gene expression and activity of detoxification enzymes as well as a wider host range and greater resistance to pesticides (Ozawa et al. 2017). The existence of a locus that can pleiotropically enhance mite adaptability suggests that selection might be able to act on limited numbers of genes to dramatically change mite host performance.

TSSM host adaptation substantially narrows genetic variation in the derived (adapted) populations (Gotoh et al. 1993). Likewise, laboratory TSSM populations typically have narrow genetic variability. Regardless, these populations usually adapt to new hosts in experimental selection experiments (Magalhães et al. 2007). If selection is the major mechanism of adaptation, then how do (isolated) TSSM populations maintain or rebuild their genetic variability? At present, the mutation rate in TSSM is not known. Transposable elements and 'mutator' loci have been postulated as generators of new genetic variation (Baym et al. 2016; Glassner et al. 1998; Schmidt et al. 2010), but their contribution to TSSM genetic variability is not known. In addition, the TSSM genome harbors expanded families of genes encoding proteins involved in the detoxification of xenobiotics, including gene clusters that appear as tandem duplications (Grbic et al. 2011). These genomic regions are prone to copy number variation and formation of chimeric genes due to unequal crossovers, potentially resulting in alleles that were shown in other herbivores to contribute to the expansion of host range (Bass et al. 2013; Joussen et al. 2012). However, the intraspecific variation at these loci has not been characterized, nor is it clear that it can contribute to TSSM host adaptation. Determination of homozygosity over time in TSSM inbred line populations, patterns and rates of newly generated genetic variation, and ability of inbred populations to adapt to new hosts will test the importance of selection on TSSM host adaptation.

It is clear spider mites do not always need to adapt to environmental changes via selection, since they display a range of plastic traits, such as detoxification mechanisms that become operational only in the presence of harmful substances (Dermauw et al. 2013; Wybouw et al. 2015). In vertebrates and insects, xenobiotic sensing is mediated by two receptor systems, the Nrf2/Keap1 (kelch-like ECH-associated protein 1-NF-E2-related factor 2 [Fuse and Kobayashi 2017; Misra et al. 2011]) and the PXR (pregnane X receptor/DHR96 [Handschin and Meyer 2003; King-Jones et al. 2006]). Xenobiotic regulation via these two classes of transcription factors differs. In the Nrf2/Keap1 system, Keap 1 is an adaptor protein that binds the xenobiotic ligand to regulate both the intracellular localization (cytoplasmic vs. nuclear) and protein stability and ubiquitination of the transcriptional activator Nrf2 (Itoh et al. 2003; Misra et al. 2011). On the other hand, direct interaction between the PXR nuclear receptor and the xenobiotic ligand enables PXR to bind to promoters of xenobioticresponsive loci (Handschin and Meyer 2003; King-Jones et al. 2006). PXR is a promiscuous receptor whose binding pocket can accept a range of ligands (Jones et al. 2000), so that PXR mediates responses to a variety of xenobiotics. Putative homologs of both these xenobiotic-sensing receptors have been identified in TSSM. However, while vertebrates and insects have only one PXR gene, there are eight PXR homologs in TSSM (Fig. 2G) (Grbic et al. 2011). Whether these nuclear receptors mediate responses to different classes of xenobiotic ligands to regulate the same or a distinct set of xenobiotic-induced genes remains to be determined. However, it is tempting to speculate that the expansion of this protein family enables TSSM to respond to a greater variety of xenobiotic molecules.

Nrf2 and PXR were shown to mediate coordinated transcriptional activation of detoxifying enzymes as well as transporters involved in the efflux of modified xenobiotics in vertebrates and insects (King-Jones et al. 2006; Misra et al. 2011). In TSSM, genes encoding detoxification enzymes as well as salivary secreted proteins (potential effectors) are among the most prominently expanded in the genome and upregulated loci upon TSSM host transfer (Fig. 2G) (Dermauw et al. 2013; Grbic et al. 2011; Wybouw et al. 2015; Zhurov et al. 2014). In other generalist herbivores (e.g., Bemisia tabaci, Helicoverpa zea) (Halon et al. 2015; Li et al. 2004b) xenobiotic responsive detoxification enzymes can modify a wide range of structurally diverse compounds. Thus, it is plausible that, upon exposure to novel hosts, TSSM induce a battery of enzymes that can neutralize host defenses, providing a sufficient fitness benefit that facilitates the (subsequent) adaptation. The substrate specificity of TSSM detoxification enzymes and the specificity of xenobiotic induction of individual members of the extended family of genes encoding detoxification enzymes have not been characterized. In humans, for example, of the $57 \mathrm{P} 450$ s, only 15 are involved in xenobiotic metabolism (Handschin and Meyer 2003). The analysis of TSSM transcriptional responses to plant phytochemicals and functional analysis of upregulated detoxification enzymes for their ability to metabolize a range of plant toxins may reveal patterns of TSSM 
xenobiotic detoxification. But, is transcriptional plasticity sufficient for the adaptation? Are these initial xenobiotic-induced genes the same (and expressed at the same level) as those that underlie the final adaptive state? If they are, then why is TSSM performance gradually improving over at least several generations upon host shift? TSSM adapted states are preserved even upon the switch to the ancestral host for one to two generations (Wybouw et al. 2015). What stabilizes this phenotypic plasticity? Are epigenetic changes also contributing to the establishment of the adaptation state? The answers to these questions await further experimentation.

\section{SUMMARY AND FUTURE DIRECTIONS}

TSSM have an extremely wide host range, but individual TSSM populations do not perform equally well across all potential plant hosts. However, TSSM populations can adapt to marginal hosts, implying that they evolved mechanisms that can overcome a diversity of initially effective plant defenses. Physical barriers to TSSM stylet penetration into the leaf mesophyll and various phytochemicals have been identified as potent constitutive defenses that can directly restrict TSSM feeding or fitness, or both. The perception of TSSM feeding triggers defenses that are primarily regulated through JA and, in some plant hosts, by SA signaling. Hormonal signaling, in turn, induces a plethora of species-specific defenses, including the accumulation of host-specific compounds, many of which remain unknown. TSSM counteradaptations to plant defenses are expected to be at least partially based on proteins secreted into the leaf tissue and on TSSM ability to manipulate plant-induced responses. In addition, expansion of families of xenobiotic sensors and detoxifying genes associate with the ability of TSSM to respond to a wide range of xenobiotics.

TSSM host adaptability is one of the salient features of TSSM polyphagy and its agricultural pest status. As such, the molecular mechanisms of its successful adaptation to a wide range of plants are the focus of current TSSM research. Identification of plant compounds with acaricidal activity, their mode of action, and TSSM targets will greatly facilitate the understanding of how plants defend themselves to restrict TSSM herbivory. On the other hand, the identification of plant targets of TSSM effectors and TSSM proteins that inactivate plant defense compounds will uncover mechanisms of TSSM counteradaptations to these defenses. The availability of a high-quality genome sequence for TSSM and genetic tools that are under development for TSSM combined with resources available in plant models (Arabidopsis, tomato, tobacco) and their integration with ecological and biochemical studies should facilitate rapid advancement in our understanding of TSSM-plant interaction.

\section{ACKNOWLEDGMENTS}

Concepts discussed in this review stem from the research that was funded by the Government of Canada through Genome Canada and the Ontario Genomics Institute (OGI-046), the Ontario Research Fund (GL2-01-035 and RE08-067) and the Natural Sciences and Engineering Research Council of Canada (NSERC) awarded to M. Grbic and V. Grbic. Authors are grateful to N. Bensoussan and $\mathrm{M}$. Cazaux for contributing parts of figures and to the anonymous reviewers for their constructive comments.

\section{LITERATURE CITED}

Abe, H., Ohnishi, J., Narusaka, M., Seo, S., Narusaka, Y., Tsuda, S., and Kobayashi, M. 2008. Function of jasmonate in response and tolerance of Arabidopsis to thrip feeding. Plant Cell Physiol. 49:68-80.

Abe, H., Shimoda, T., Ohnishi, J., Kugimiya, S., Narusaka, M., Seo, S., Narusaka, Y., Tsuda, S., and Kobayashi, M. 2009. Jasmonate-dependent plant defense restricts thrips performance and preference. BMC Plant Biol. 9:97.

Agrawal, A. A. 2000. Host-range evolution: Adaptation and trade-offs in fitness of mites on alternative hosts. Ecology 81:500-8.
Agrawal, A. A., Vala, F., and Sabelis, M. W. 2002. Induction of preference and performance after acclimation to novel hosts in a phytophagous spider mite: Adaptive plasticity? Am. Nat. 159:553-65.

Agut, B., Gamir, J., Jaques, J. A., and Flors, V. 2015. Tetranychus urticaetriggered responses promote genotype-dependent conspecific repellence or attractiveness in citrus. New Phytol. 207:790-804.

Agut, B., Gamir, J., Jaques, J. A., and Flors, V. 2016. Systemic resistance in citrus to Tetranychus urticae induced by conspecifics is transmitted by grafting and mediated by mobile amino acids. J. Exp. Bot. 67:5711-5723.

Agut, B., Gamir, J., Jacas, J. A., Hurtado, M., and Flors, V. 2014. Different metabolic and genetic responses in citrus may explain relative susceptibility to Tetranychus urticae. Pest Manag. Sci. 70:1728-41.

Alba, J. M., Schimmel, B. C., Glas, J. J., Ataide, L. M., Pappas, M. L., Villarroel, C. A., Schuurink, R. C., Sabelis, M. W., and Kant, M. R. 2015. Spider mites suppress tomato defenses downstream of jasmonate and salicylate independently of hormonal crosstalk. New Phytol. 205:828-40.

Ament, K., Kant, M. R., Sabelis, M. W., Haring, M. A., and Schuurink, R. C. 2004. Jasmonic acid is a key regulator of spider mite-induced volatile terpenoid and methyl salicylate emission in tomato. Plant Physiol. 135:2025-37.

Ament, K., Krasikov, V., Allmann, S., Rep, M., Takken, F. L., and Schuurink, R. C. 2010. Methyl salicylate production in tomato affects biotic interactions. Plant J. 62:124-34.

Antonious, G. F., Kamminga, K., and Snyder, J. C. 2014. Wild tomato leaf extracts for spider mite and cowpea aphid control. J. Environ. Sci. Health 49:527-31.

Arena, G. D., Ramos-Gonzalez, P. L., Nunes, M. A., Ribeiro-Alves, M., Camargo, L. E., Kitajima, E. W., Machado, M. A., and Freitas-Astua, J. 2016. Citrus leprosis virus $C$ infection results in hypersensitive-like response, suppression of the JA/ET plant defense pathway and promotion of the colonization of its mite vector. Front. Plant Sci. 7:1757.

Balkema-Boomstra, A. G., Zijlstra, S., Verstappen, F. W., Inggamer, H., Mercke, P. E., Jongsma, M. A., and Bouwmeester, H. J. 2003. Role of cucurbitacin $\mathrm{C}$ in resistance to spider mite (Tetranychus urticae) in cucumber (Cucumis sativus L.). J. Chem. Ecol. 29:225-35.

Barrett, L. G., and Heil, M. 2012. Unifying concepts and mechanisms in the specificity of plant-enemy interactions. Trends Plant Sci. 17:282-92.

Bass, C., Zimmer, C. T., Riveron, J. M., Wilding, C. S., Wondji, C. S., Kaussmann, M., Field, L. M., Williamson, M. S., and Nauen, R. 2013. Gene amplification and microsatellite polymorphism underlie a recent insect host shift. Proc. Natl. Acad. Sci. U.S.A. 110:19460-5.

Baym, M., Lieberman, T. D., Kelsic, E. D., Chait, R., Gross, R., Yelin, I., and Kishony, R. 2016. Spatiotemporal microbial evolution on antibiotic landscapes. Science 353:1147-51.

Beard, J. J., Ochoa, R., Bauchan, G. R., Welbourn, W. C., Pooley, C., and Dowling, A. P. G. 2012. External mouthpart morphology in the Tenuipalpidae (Tetranychoidea): Raoiella a case study. Exp. Appl. Acarol. 57:227-55.

Bender, J., and Fink, G. R. 1998. A Myb homologue, ATR1, activates tryptophan gene expression in Arabidopsis. Proc. Natl. Acad. Sci. U.S.A. 95:5655-60.

Bensoussan, N., Santamaría, M. E., Zhurov, V., Diaz, I., Grbic, M., and Grbic, V. 2016. Plant-herbivore interaction: Dissection of the cellular pattern of Tetranychus urticae feeding on the host plant. Front. Plant Sci. 7:1105

Bernays, E., and Graham, M. 1988. On the evolution of host specificity in phytophagous arthropods. Ecology 69:886-92.

Bleeker, P. M., Mirabella, R., Diergaarde, P. J., VanDoorn, A., Tissier, A., Kant, M. R., Prins, M., De Vos, M., Haring, M. A., and Schuurink, R. C 2012. Improved herbivore resistance in cultivated tomato with the sesquiterpene biosynthetic pathway from a wild relative. Proc. Natl. Acad. Sci. U.S.A. 109:20124-9

Boller, T., and Felix, G. 2009. A renaissance of elicitors: Perception of microbe-associated molecular patterns and danger signals by patternrecognition receptors. Annu. Rev. Plant Biol. 60:379-406.

Bos, J. I. B., Prince, D., Pitino, M., Maffei, M. E., Win, J., and Hogenhout, S. A. 2010. A functional genomics approach identifies candidate effectors from the aphid species Myzus persicae (green peach aphid). PLoS Genet. 6:e1001216.

Brader, G., Tas, É., and Palva, E. T. 2001. Jasmonate-dependent induction of indole glucosinolates in Arabidopsis by culture filtrates of the nonspecific pathogen Erwinia carotovora. Plant Physiol. 126:849-60.

Breeuwer, J. A. J. 1997. Wolbachia and cytoplasmic incompatibility in the spider mites Tetranychus urticae and T. turkestani. Heredity 79:41-7.

Carrillo, L., Martinez, M., Ramessar, K., Cambra, I., Castanera, P., Ortego, F., and Diaz, I. 2011. Expression of a barley cystatin gene in maize enhances resistance against phytophagous mites by altering their cysteine-proteases. Plant Cell Rep. 30:101-12. 
Chatzivasileiadis, E. A., and Sabelis, M. W. 1997. Toxicity of methyl ketones from tomato trichomes to Tetranychus urticae Koch. Exp. Appl. Acarol. 21:473-84.

Chaudhary, R., Atamian, H. S., Shen, Z., Briggs, S. P., and Kaloshian, I. 2014. GroEL from the endosymbiont Buchnera aphidicola betrays the aphid by triggering plant defense. Proc. Natl. Acad. Sci. U.S.A. 111:8919-24.

Chen, H., Gonzales-Vigil, E., Wilkerson, C. G., and Howe, G. A. 2007. Stability of plant defense proteins in the gut of insect herbivores. Plant Physiology 143:1954-1967.

Chen, H., Jones, A. D., and Howe, G. A. 2006. Constitutive activation of the jasmonate signaling pathway enhances the production of secondary metabolites in tomato. FEBS Lett. 580:2540-6.

Chen, H., McCaig, B. C., Melotto, M., He, S. Y., and Howe, G. A. 2004. Regulation of plant arginase by wounding, jasmonate, and the phytotoxin coronatine. J. Biol. Chem. 279:45998-46007.

Chung, S. H., Rosa, C., Hoover, K., Luthe, D. S., and Felton, G. W. 2013 a. Colorado potato beetle manipulates plant defenses in local and systemic leaves. Plant Signal. Behav. 8:e27592.

Chung, S. H., Rosa, C., Scully, E. D., Peiffer, M., Tooker, J. F., Hoover, K., Luthe, D. S., and Felton, G. W. 2013b. Herbivore exploits orally secreted bacteria to suppress plant defenses. Proc. Natl. Acad. Sci. U.S.A. 110: 15728-33.

Consales, F., Schweizer, F., Erb, M., Gouhier-Darimont, C., Bodenhausen, N., Bruessow, F., Sobhy, I., and Reymond, P. 2012. Insect oral secretions suppress wound-induced responses in Arabidopsis. J. Exp. Bot. 63:727-37.

Coppola, V., Coppola, M., Rocco, M., Digilio, M. C., D’Ambrosio, C., Renzone, G., Martinelli, R., Scaloni, A., Pennacchio, F., Rao, R., and Corrado, G. 2013. Transcriptomic and proteomic analysis of a compatible tomato-aphid interaction reveals a predominant salicylic acid-dependent plant response. BMC Genomics 14:515.

Da Costa, C. P., and Jones, C. M. 1971. Cucumber beetle resistance and mite susceptibility controlled by the bitter gene in Cucumis sativus L. Science 172:1145-6.

Dafoe, N. J., Thomas, J. D., Shirk, P. D., Legaspi, M. E., Vaughan, M. M., Huffaker, A., Teal, P. E., and Schmelz, E. A. 2013. European corn borer (Ostrinia nubilalis) induced responses enhance susceptibility in maize. PLoS One 8:e73394.

De Vos, M., Van Oosten, V. R., Van Poecke, R. M. P., Van Pelt, J. A., Pozo, M. J., Mueller, M. J., Buchala, A. J., Metraux, J. P., Van Loon, L. C., Dicke, M., and Pieterse, C. M. J. 2005. Signal signature and transcriptome changes of Arabidopsis during pathogen and insect attack. 18:923-37.

Dermauw, W., Wybouw, N., Rombauts, S., Menten, B., Vontas, J., Grbic, M., Clark, R. M., Feyereisen, R., and Van Leeuwen, T. 2013. A link between host plant adaptation and pesticide resistance in the polyphagous spider mite Tetranychus urticae. Proc. Natl. Acad. Sci. U.S.A. 110:E113-22.

Diaz-Riquelme, J., Zhurov, V., Rioja, C., Perez-Moreno, I., Torres-Perez, R., Grimplet, J., Carbonell-Bejerano, P., Bajda, S., Van Leeuwen, T., Martinez-Zapater, J. M., Grbic, M., and Grbic, V. 2016. Comparative genome-wide transcriptome analysis of Vitis vinifera responses to adapted and non-adapted strains of two-spotted spider mite, Tetranyhus urticae. BMC Genomics 17:74.

Dobler, S., Dalla, S., Wagschal, V., and Agrawal, A. A. 2012. Community-wide convergent evolution in insect adaptation to toxic cardenolides by substitutions in the Na,K-ATPase. Proc. Natl. Acad. Sci. U.S.A. 109:13040-5.

Ellis, C., Karafyllidis, I., and Turner, J. G. 2002. Constitutive activation of jasmonate signaling in an Arabidopsis mutant correlates with enhanced resistance to Erysiphe cichoracearum, Pseudomonas syringae, and Myzus persicae. Mol. Plant-Microbe Interact. 15:1025-30.

Elzinga, D. A., and Jander, G. 2013. The role of protein effectors in plantaphid interactions. Curr. Opin. Plant Biol. 16:451-6.

Elzinga, D. A., De Vos, M., and Jander, G. 2014. Suppression of plant defenses by a Myzus persicae (green peach aphid) salivary effector protein. Mol. Plant-Microbe Interact. 27:747-56.

Enigl, M., and Schausberger, P. 2007. Incidence of the endosymbionts Wolbachia, Cardinium and Spiroplasma in phytoseiid mites and associated prey. Exp. Appl. Acarol. 42:75-85.

Erb, M., Meldau, S., and Howe, G. A. 2012. Role of phytohormones in insect-specific plant reactions. Trends Plant Sci. 17:250-9.

Erban, T., and Hubert, J. 2010. Determination of $\mathrm{pH}$ in regions of the midguts of acaridid mites. J. Insect Sci. 10:42.

Fan, P. X., Miller, A. M., Schilmiller, A. L., Liu, X. X., Ofner, I., Jones, A. D., Zamir, D., and Last, R. L. 2016. In vitro reconstruction and analysis of evolutionary variation of the tomato acylsucrose metabolic network. Proc. Natl. Acad. Sci. U.S.A. 113:E239-E248.

Fellous, S., Angot, G., Orsucci, M., Migeon, A., Auger, P., Olivieri, I., and Navajas, M. 2014. Combining experimental evolution and field population assays to study the evolution of host range breadth. J. Evol. Biol. 27:911-9.
Felton, G. W., Donato, K. K., Broadway, R. M., and Duffey, S. S. 1992. Impact of oxidized plant phenolics on the nutritional quality of dietary protein to a noctuid herbivore, Spodoptera exigua. J. Insect Physiol. 38:277-285.

Felton, G. W., Chung, S. H., Hernandez, M. G. E., Louis, J., Peiffer, M., and Tian, D. 2014. Herbivore oral secretions are the first line of protection against plant-induced defences. Pages 37-76 in: Annual Plant Reviews. C. Voelckel and G. Jander, eds. John Wiley \& Sons, Ltd., Chichester, U.K.

Fry, J. D. 1989. Evolutionary adaptation to host plants in a laboratory population of the phytophagous mite Tetranychus urticae Koch. Oecologia 81:559-65.

Furch, A. C., van Bel, A. J., and Will, T. 2015. Aphid salivary proteases are capable of degrading sieve-tube proteins. J. Exp. Bot. 66:533-9.

Fuse, Y., and Kobayashi, M. 2017. Conservation of the Keap1-Nrf2 system: An evolutionary journey through stressful space and time. Molecules 22:436.

Futuyma, D. J., and Gould, F. 1979. Associations of plants and insects in deciduous forest. Ecol. Monogr. 49:33-50.

Ghosh, B., Westbrook, T. C., and Jones, A. D. 2014. Comparative structural profiling of trichome specialized metabolites in tomato (Solanum lycopersicum) and $S$. habrochaites: Acylsugar profiles revealed by UHPLC/MS and NMR. Metabolomics 10:496-507.

Giordanengo, P., Brunissen, L., Rusterucci, C., Vincent, C., van Bel, A., Dinant, S., Girousse, C., Faucher, M., and Bonnemain, J. L. 2010. Compatible plant-aphid interactions: How aphids manipulate plant responses. C. R. Biol. 333:516-23.

Glas, J. J., Alba, J. M., Simoni, S., Villarroel, C. A., Stoops, M., Schimmel, B. C., Schuurink, R. C., Sabelis, M. W., and Kant, M. R. 2014. Defense suppression benefits herbivores that have a monopoly on their feeding site but can backfire within natural communities. BMC Biol. 12:98.

Glassner, B. J., Rasmussen, L. J., Najarian, M. T., Posnick, L. M., and Samson, L. D. 1998. Generation of a strong mutator phenotype in yeast by imbalanced base excision repair. Proc. Natl. Acad. Sci. U.S.A. 95:9997-10002.

Gonzales-Vigil, E., Bianchetti, C. M., Phillips, G. N., Jr., and Howe, G. A. 2011. Adaptive evolution of threonine deaminase in plant defense against insect herbivores. Proc. Natl. Acad. Sci. U.S.A. 108:5897-902.

Gotoh, T., Noda, H., and Hong, X. Y. 2003. Wolbachia distribution and cytoplasmic incompatibility based on a survey of 42 spider mite species (Acari: Tetranychidae) in Japan. Heredity 91:208-16.

Gotoh, T., Noda, H., and Ito, S. 2007. Cardinium symbionts cause cytoplasmic incompatibility in spider mites. Heredity 98:13-20.

Gotoh, T., Bruin, J., Sabelis, M. W., and Menken, S. B. J. 1993. Host race formation in Tetranychus urticae: Genetic differentiation, host plant preference, and mate choice in a tomato and a cucumber strain. Entomol. Exp. Appl. 68:171-8.

Grbic, M., Van Leeuwen, T., Clark, R. M., Rombauts, S., Rouze, P., Grbic, V., Osborne, E. J., Dermauw, W., Ngoc, P. C., Ortego, F., HernandezCrespo, P., Diaz, I., Martinez, M., Navajas, M., Sucena, E., Magalhães, S., Nagy, L., Pace, R. M., Djuranovic, S., Smagghe, G., Iga, M., Christiaens, O., Veenstra, J. A., Ewer, J., Villalobos, R. M., Hutter, J. L., Hudson, S. D., Velez, M., Yi, S. V., Zeng, J., Pires-daSilva, A., Roch, F., Cazaux, M., Navarro, M., Zhurov, V., Acevedo, G., Bjelica, A., Fawcett, J. A., Bonnet, E., Martens, C., Baele, G., Wissler, L., SanchezRodriguez, A., Tirry, L., Blais, C., Demeestere, K., Henz, S. R., Gregory, T. R., Mathieu, J., Verdon, L., Farinelli, L., Schmutz, J., Lindquist, E., Feyereisen, R., and Van de Peer, Y. 2011. The genome of Tetranychus urticae reveals herbivorous pest adaptations. Nature 479:487-92.

Gu, Y. Q., Holzer, F. M. and Walling, L. L. 1999. Overexpression, purification and biochemical characterization of the wound-induced leucine aminopeptidase of tomato. FEBS J. 263:726-735.

Guo, H., Wielsch, N., Hafke, J. B., Svatos, A., Mithofer, A., and Boland, W. 2013. A porin-like protein from oral secretions of Spodoptera littoralis larvae induces defense-related early events in plant leaves. Insect Biochem. Mol. Biol. 43:849-58.

Halon, E., Eakteiman, G., Moshitzky, P., Elbaz, M., Alon, M., Pavlidi, N., Vontas, J., and Morin, S. 2015. Only a minority of broad-range detoxification genes respond to a variety of phytotoxins in generalist Bemisia tabaci species. Sci. Rep. 5:17975

Handschin, C., and Meyer, U. A. 2003. Induction of drug metabolism: The role of nuclear receptors. Pharmacol. Rev. 55:649-73.

Heidel-Fischer, H. M., and Vogel, H. 2015. Molecular mechanisms of insect adaptation to plant secondary compounds. Curr. Opin. Insect Sci. 8:8-14.

Hogenhout, S. A., and Bos, J. I. 2011. Effector proteins that modulate plantinsect interactions. Curr. Opin. Plant Biol. 14:422-8.

Howe, G. A., Lightner, J., Browse, J., and Ryan, C. A. 1996. An octadecanoid pathway mutant (JL5) of tomato is compromised in signaling for defense against insect attack. Plant Cell 8:2067-77.

Itoh, K., Wakabayashi, N., Katoh, Y., Ishii, T., O'Connor, T., and Yamamoto, M. 2003. Keap1 regulates both cytoplasmic-nuclear shuttling and degradation of Nrf2 in response to electrophiles. Genes Cells 8:379-91. 
Jonckheere, W., Dermauw, W., Zhurov, V., Wybouw, N., Van den Bulcke, J., Villarroel, C. A., Greenhalgh, R., Grbic, M., Schuurink, R. C., Tirry, L., Baggerman, G., Clark, R. M., Kant, M. R., Vanholme, B., Menschaert, G., and Van Leeuwen, T. 2016. The salivary protein repertoire of the polyphagous spider mite Tetranychus urticae: A quest for effectors. Mol. Cell. Proteomics 25:3594-3613.

Jones, S. A., Moore, L. B., Shenk, J. L., Wisely, G. B., Hamilton, G. A., McKee, D. D., Tomkinson, N. C., LeCluyse, E. L., Lambert, M. H., Willson, T. M., Kliewer, S. A., and Moore, J. T. 2000. The pregnane $\mathrm{X}$ receptor: A promiscuous xenobiotic receptor that has diverged during evolution. Mol. Endocrinol. 14:27-39.

Joussen, N., Agnolet, S., Lorenz, S., Schone, S. E., Ellinger, R., Schneider, B., and Heckel, D. G. 2012. Resistance of Australian Helicoverpa armigera to fenvalerate is due to the chimeric P450 enzyme CYP337B3. Proc. Natl. Acad. Sci. U.S.A. 109:15206-11.

Kaloshian, I., and Walling, L. L. 2016. Hemipteran and dipteran pests: Effectors and plant host immune regulators. J. Integr. Plant Biol. 58:350-61.

Kandoth, P. K., Ranf, S., Pancholi, S. S., Jayanty, S., Walla, M. D., Miller, W., Howe, G. A., Lincoln, D. E., and Stratmann, J. W. 2007. Tomato MAPKs LeMPK1, LeMPK2, and LeMPK3 function in the systeminmediated defense response against herbivorous insects. Proc. Natl. Acad. Sci. U.S.A. 104:12205-10.

Kant, M. R., Sabelis, M. W., Haring, M. A., and Schuurink, R. C. 2008. Intraspecific variation in a generalist herbivore accounts for differential induction and impact of host plant defences. P. Roy. Soc. B-Biol. Sci. 275:443-452.

Kant, M. R., Ament, K., Sabelis, M. W., Haring, M. A., and Schuurink, R. C. 2004. Differential timing of spider mite-induced direct and indirect defenses in tomato plants. Plant Physiol. 135:483-95.

Kempema, L. A., Cui, X., Holzer, F. M., and Walling, L. L. 2007. Arabidopsis transcriptome changes in response to phloem-feeding silverleaf whitefly nymphs. Similarities and distinctions in responses to aphids. Plant Physiol. 143:849-65.

Kielkiewicz, M., and van de Vrie, M. 1990. Within-leaf differences in nutritive value and defence mechanism in chrysanthemum to the twospotted spider mite (Tetranychus urticae). Exp. Appl. Acarol. 10:33-43.

Kindt, F., Joosten, N. N., Peters, D., and Tjallingii, W. F. 2003. Characterisation of the feeding behaviour of western flower thrips in terms of electrical penetration graph (EPG) waveforms. J. Insect Physiol. 49:183-91.

King-Jones, K., Horner, M. A., Lam, G., and Thummel, C. S. 2006. The DHR96 nuclear receptor regulates xenobiotic responses in Drosophila. Cell Metab. 4:37-48.

Koeduka, T., Sugimoto, K., Watanabe, B., Someya, N., Kawanishi, D., Gotoh, T., Ozawa, R., Takabayashi, J., Matsui, K., and Hiratake, J. 2014. Bioactivity of natural $O$-prenylated phenylpropenes from Illicium anisatum leaves and their derivatives against spider mites and fungal pathogens. Plant Biol. 16:451-6.

Koramutla, M. K., Kaur, A., Negi, M., Venkatachalam, P., and Bhattacharya, R. 2014. Elicitation of jasmonate-mediated host defense in Brassica juncea (L.) attenuates population growth of mustard aphid Lipaphis erysimi (Kalt.). Planta 240:177-94.

Kos, S. P., Klinkhamer, P. G. L., and Leiss, K. A. 2014. Cross-resistance of chrysanthemum to western flower thrips, celery leafminer, and twospotted spider mite. Entomol. Exp. Appl. 151:198-208.

Kwon, D. H., Park, J. H., and Lee, S. H. 2013. Screening of lethal genes for feeding RNAi by leaf disc-mediated systematic delivery of dsRNA in Tetranychus urticae. Pestic. Biochem. Physiol. 105:69-75.

Kwon, D. H., Park, J. H., Ashok, P. A., Lee, U., and Lee, S. H. 2015. Screening of target genes for RNAi in Tetranychus urticae and RNAi toxicity enhancement by chimeric genes. Pestic. Biochem. Physiol. 16:1-7.

Li, C. Y., Williams, M. M., Loh, Y. T., Lee, G. I., and Howe, G. A. 2002. Resistance of cultivated tomato to cell content-feeding herbivores is regulated by the octadecanoid-signaling pathway. Plant Physiol. 130:494-503.

Li, L., Zhao, Y. F., McCaig, B. C., Wingerd, B. A., Wang, J. H., Whalon, M. E., Pichersky, E., and Howe, G. A. 2004a. The tomato homolog of CORONATINE-INSENSITIVE1 is required for the maternal control of seed maturation, jasmonate-signaled defense responses, and glandular trichome development. Plant Cell 16:126-143.

Li, X., Zangerl, A. R., Schuler, M. A., and Berenbaum, M. R. 2000. Crossresistance to $\alpha$-cypermethrin after xanthotoxin ingestion in Helicoverpa zea (Lepidoptera: Noctuidae). J. Econ. Entomol. 93:18-25.

Li, X., Baudry, J., Berenbaum, M. R., and Schuler, M. A. 2004b. Structural and functional divergence of insect CYP6B proteins: From specialist to generalist cytochrome P450. Proc. Natl. Acad. Sci. U.S.A. 101:2939-44.

Magalhães, S., Blanchet, E., Egas, M., and Olivieri, I. 2009. Are adaptation costs necessary to build up a local adaptation pattern? BMC Evol. Biol. 9:182.

Magalhães, S., Fayard, J., Janssen, A., Carbonell, D., and Olivieri, I. 2007. Adaptation in a spider mite population after long-term evolution on a single host plant. J. Evol. Biol. 20:2016-27.
Mao, W., Rupasinghe, S. G., Zangerl, A. R., Berenbaum, M. R., and Schuler, M. A. 2007. Allelic variation in the Depressaria pastinacella CYP6AB3 protein enhances metabolism of plant allelochemicals by altering a proximal surface residue and potential interactions with cytochrome P450 reductase. J. Biol. Chem. 282:10544-10552.

Marriott, J., Florentine, S., and Raman, A. 2013. Effects of Tetranychus lintearius (Acari: Tetranychidae) on the structure and water potential in the foliage of the invasive Ulex europaeus (Fabaceae) in Australia. Int. J. Acarol. 39:275-84

Martel, C., Zhurov, V., Navarro, M., Martinez, M., Cazaux, M., Auger, P., Migeon, A., Santamaría, M. E., Wybouw, N., Diaz, I., Van Leeuwen, T., Navajas, M., Grbic, M., and Grbic, V. 2015. Tomato whole genome transcriptional response to Tetranychus urticae identifies divergence of spider mite-induced responses between tomato and Arabidopsis. Mol Plant-Microbe Interact. 28:343-61.

Migeon, A., and Dorkeld, F. 2010. Spider mites web: A comprehensive database for the Tetranychidae. Pages 557-560 in: Trends in Acarology: Proceedings of the 12th International Congress, M. W. Sabelis and J. Bruin, eds. Springer Netherlands, Amsterdam.

Misra, J. R., Horner, M. A., Lam, G., and Thummel, C. S. 2011. Transcriptional regulation of xenobiotic detoxification in Drosophila. Genes Dev. 25:1796-806.

Mithofer, A., and Boland, W. 2008. Recognition of herbivory-associated molecular patterns. Plant Physiol. 146:825-31.

Navajas, M. 1999. Host plant associations in the spider mite Tetranychus urticae (Acari: Tetranychidae): insights from molecular phylogeography. Pages 163-174 in: Ecology and Evolution of the Acari: Proceedings of the 3rd Symposium of the European Association of Acarologists 1-July 5, 1996, Amsterdam, The Netherlands, J. Bruin, L. P. S. van der Geest, and M. W. Sabelis, eds. Springer Netherlands, Dordrecht, The Netherlands.

Ozawa, R., Endo, H., Iijima, M., Sugimoto, K., Takabayashi, J., Gotoh, T., and Arimura, G. I. 2017. Intraspecific variation among Tetranychid mites for ability to detoxify and to induce plant defenses. Sci. Rep. 7:43200.

Park, J. H., Halitschke, R., Kim, H. B., Baldwin, I. T., Feldmann, K. A., and Feyereisen, R. 2002. A knock-out mutation in allene oxide synthase results in male sterility and defective wound signal transduction in Arabidopsis due to a block in jasmonic acid biosynthesis. Plant J. 31:1-12.

Pentzold, S., Zagrobelny, M., Roelsgaard, P. S., Møller, B. L., and Bak, S. 2014. The multiple strategies of an insect herbivore to overcome plant cyanogenic glucoside defence. PLoS One 9:e91337.

Pentzold, S., Zagrobelny, M., Bjarnholt, N., Kroymann, J., Vogel, H., Olsen, C. E., Moller, B. L., and Bak, S. 2015. Metabolism, excretion and avoidance of cyanogenic glucosides in insects with different feeding specialisations. Insect Biochem. Mol. Biol. 66:119-28.

Puterka, G. J., Farone, W., Palmer, T., and Barrington, A. 2003. Structurefunction relationships affecting the insecticidal and miticidal activity of sugar esters. J. Econ. Entomol. 96:636-44.

Ray, S., Gaffor, I., Acevedo, F. E., Helms, A., Chuang, W. P., Tooker, J., Felton, G. W., and Luthe, D. S. 2015. Maize plants recognize herbivoreassociated cues from caterpillar frass. J. Chem. Ecol. 41:781-92.

Ray, S., Alves, P. C., Ahmad, I., Gaffoor, I., Acevedo, F. E., Peiffer, M., Jin, S., Han, Y., Shakeel, S., Felton, G. W., and Luthe, D. S. 2016. Turnabout is fair play: Herbivory-induced plant chitinases excreted in fall armyworm frass suppress herbivore defenses in maize. Plant Physiol. 171:694-706.

Resende, J. T., Maluf, W. R., Cardoso, M., Nelson, D. L., and Faria, M. V. 2002. Inheritance of acyl sugar contents in tomatoes derived from an interspecific cross with the wild tomato Lycopersicon pennellii and their effect on spider mite repellence. Genet. Mol. Res. 1:106-16.

Salinas, M., Capel, C., Alba, J. M., Mora, B., Cuartero, J., FernandezMunoz, R., Lozano, R., and Capel, J. 2013. Genetic mapping of two QTL from the wild tomato Solanum pimpinellifolium $\mathrm{L}$. controlling resistance against two-spotted spider mite (Tetranychus urticae Koch). Theor Appl. Genet. 126:83-92.

Santamaría, M. E., Gonzalez-Cabrera, J., Martinez, M., Grbic, V., Castanera, P., Diaz, L., and Ortego, F. 2015. Digestive proteases in bodies and faeces of the two-spotted spider mite, Tetranychus urticae. J. Insect Physiol. 78:69-77.

Santamaría, M. E., Martinez, M., Arnaiz, A., Ortego, F., Grbic, V., and Diaz, I. 2017a. MATI, a novel protein involved in the regulation of herbivore-associated signaling pathways. Front. Plant Sci. 8:975.

Santamaría, M. E., Auger, P., Martínez, M., Migeon, A., Castañera, P., Díaz, I., Navajas, M., and Ortego, F. 2017b. Host plant use by two distinct lineages of the tomato red spider mite, Tetranychus evansi, differing in their distribution range. J. Pest Sci. Published online. 10.1007/s10340017-0852-1

Sarmento, R. A., Lemos, F., Bleeker, P. M., Schuurink, R. C., Pallini, A., Oliveira, M. G., Lima, E. R., Kant, M., Sabelis, M. W., and Janssen, A. 2011. A herbivore that manipulates plant defence. Ecol. Lett. 14:229-236. 
Schimmel, B. C. J., Ataide, L. M. S., Chafi, R., Villarroel, C. A., Alba, J. M., Schuurink, R. C., and Kant, M. R. 2017. Overcompensation of herbivore reproduction through hyper-suppression of plant defenses in response to competition. New Phytol. 214:1688-701.

Schmelz, E. A., Huffaker, A., Carroll, M. J., Alborn, H. T., Ali, J. G., and Teal, P. E. 2012. An amino acid substitution inhibits specialist herbivore production of an antagonist effector and recovers insect-induced plant defenses. Plant Physiol. 160:1468-78.

Schmelz, E. A., Carroll, M. J., LeClere, S., Phipps, S. M., Meredith, J., Chourey, P. S., Alborn, H. T., and Teal, P. E. A. 2006. Fragments of ATP synthase mediate plant perception of insect attack. Proc. Natl. Acad. Sci. U.S.A. 103:8894-9.

Schmidt, J. M., Good, R. T., Appleton, B., Sherrard, J., Raymant, G. C., Bogwitz, M. R., Martin, J., Daborn, P. J., Goddard, M. E., Batterham, P., and Robin, C. 2010. Copy number variation and transposable elements feature in recent, ongoing adaptation at the Cyp6g1 locus. PLoS Genet. 6:e1000998.

Schweighofer, A., Kazanaviciute, V., Scheikl, E., Teige, M., Doczi, R., Hirt, H., Schwanninger, M., Kant, M., Schuurink, R., Mauch, F., Buchala, A., Cardinale, F., and Meskiene, I. 2007. The PP2C-type phosphatase AP2C1, which negatively regulates $M P K 4$ and $M P K 6$, modulates innate immunity, jasmonic acid, and ethylene levels in Arabidopsis. Plant Cell 19:2213-24.

Scranton, K., Stavrinides, M., Mills, N. J., and de Valpine, P. 2013. Smallscale intraspecific life history variation in herbivorous spider mites (Tetranychus pacificus) is associated with host plant cultivar. PLoS One 8:e72980.

Staudacher, H., Schimmel, B. C., Lamers, M. M., Wybouw, N., Groot, A. T., and Kant, M. R. 2017. Independent effects of a herbivore's bacterial symbionts on its performance and induced plant defences. Int. J. Mol. Sci. 18:182

Sterck, L., Billiau, K., Abeel, T., Rouze, P., and Van de Peer, Y. 2012. ORCAE: Online resource for community annotation of eukaryotes. Nat. Methods 9:1041.

Suzuki, T., Espana, M. U., Nunes, M. A., Zhurov, V., Dermauw, W., Osakabe, M., Van Leeuwen, T., Grbic, M., and Grbic, V. 2017a. Protocols for the delivery of small molecules to the two-spotted spider mite, Tetranychus urticae. PLoS One 12:e0180658.

Suzuki, T., Nunes, M. A., Espana, M. U., Namin, H. H., Jin, P., Bensoussan, N., Zhurov, V., Rahman, T., De Clercq, R., Hilson, P., Grbic, V., and Grbic, M. 2017b. RNAi-based reverse genetics in the chelicerate model Tetranychus urticae: A comparative analysis of five methods for gene silencing. PLoS One 12:e0180654.

Tanigoshi, L. K., and Davis, R. W. 1978. An ultrastructural study of Tetranychus mcdanieli feeding injury to the leaves of 'Red Delicious' apple (Acari: Tetranychidae). Int. J. Acarol. 4:47-51.

Van Leeuwen, T., and Dermauw, W. 2016. The molecular evolution of xenobiotic metabolism and resistance in chelicerate mites. Annu. Rev. Entomol. 61:475-98.

Van Leeuwen, T., Demaeght, P., Osborne, E. J., Dermauw, W., Gohlke, S., Nauen, R., Grbić, M., Tirry, L., Merzendorfer, H., and Clark, R. M. 2012 Population bulk segregant mapping uncovers resistance mutations and the mode of action of a chitin synthesis inhibitor in arthropods. Proc. Natl. Acad. Sci. U.S.A. 109:4407-12.

Verhage, A., Vlaardingerbroek, I., Raaymakers, C., Van Dam, N. M., Dicke, M., Van Wees, S. C., and Pieterse, C. M. 2011. Rewiring of the jasmonate signaling pathway in Arabidopsis during insect herbivory. Front. Plant Sci. 2:47.

Villarroel, C. A., Jonckheere, W., Alba, J. M., Glas, J. J., Dermauw, W., Haring, M. A., Van Leeuwen, T., Schuurink, R. C., and Kant, M. R. 2016. Salivary proteins of spider mites suppress defenses in Nicotiana benthamiana and promote mite reproduction. Plant J. 86:119-31.

Vos, I. A., Verhage, A., Schuurink, R. C., Watt, L. G., Pieterse, C. M. J., and Van Wees, S. C. M. 2013. Onset of herbivore-induced resistance in systemic tissue primed for jasmonate-dependent defenses is activated by abscisic acid. Front. Plant Sci. 4:539.

Walling, L. L. 2000. The myriad plant responses to herbivores. J. Plant Growth Regul. 19:195-216.

Walling, L. L. 2008. Avoiding effective defenses: Strategies employed by phloem-feeding insects. Plant Physiol. 146:859-66.

Wan, J. R., Tanaka, K., Zhang, X. C., Son, G. H., Brechenmacher, L., Tran, H. N. N., and Stacey, G. 2012. LYK4, a lysin motif receptor-like kinase, is important for chitin signaling and plant innate immunity in Arabidopsis. Plant Physiol. 160:396-406.

Wei, J., van Loon, J. J., Gols, R., Menzel, T. R., Li, N., Kang, L., and Dicke, M. 2014. Reciprocal crosstalk between jasmonate and salicylate defence-signalling pathways modulates plant volatile emission and herbivore host-selection behaviour. J. Exp. Bot. 65:3289-98.

Weinert, L. A., Werren, J. H., Aebi, A., Stone, G. N., and Jiggins, F. M. 2009. Evolution and diversity of Rickettsia bacteria. BMC Biol. 7:6.

Will, T., Furch, A. C., and Zimmermann, M. R. 2013. How phloem-feeding insects face the challenge of phloem-located defenses. Front. Plant Sci. 4:336

Williams, C. E., Nemacheck, J. A., Shukle, J. T., Subramanyam, S. Saltzmann, K. D., and Shukle, R. H. 2011. Induced epidermal permeability modulates resistance and susceptibility of wheat seedlings to herbivory by Hessian fly larvae. J. Exp. Bot. 62:4521-31.

Williams, W. G., Kennedy, G. G., Yamamoto, R. T., Thacker, J. D., and Bordner, J. 1980. 2-Tridecanone: A naturally occurring insecticide from the wild tomato Lycopersicon hirsutum f.glabratum. Science 207:888-9.

Wu, S., Peiffer, M., Luthe, D. S., and Felton, G. W. 2012. ATP hydrolyzing salivary enzymes of caterpillars suppress plant defenses. PLoS One 7:e41947.

Wybouw, N., Dermauw, W., Tirry, L., Stevens, C., Grbic, M., Feyereisen, R., and Van Leeuwen, T. 2014. A gene horizontally transferred from bacteria protects arthropods from host plant cyanide poisoning. eLife 3:e02365.

Wybouw, N., Zhurov, V., Martel, C., Bruinsma, K. A., Hendrickx, F., Grbic, V., and Van Leeuwen, T. 2015. Adaptation of a polyphagous herbivore to a novel host plant extensively shapes the transcriptome of herbivore and host. Mol. Ecol. 24:4647-63.

Xémenez-Embún, M. G., Castanera, P., and Ortego, F. 2017. Drought stress in tomato increases the performance of adapted and non-adapted strains of Tetranychus urticae. J. Insect Physiol. 96:73-81.

Yang, F., Zhang, Y., Huang, Q., Yin, G., Pennerman, K. K., Yu, J., Liu, Z., Li, D., and Guo, A. 2015. Analysis of key genes of jasmonic acid mediated signal pathway for defense against insect damages by comparative transcriptome sequencing. Sci. Rep. 5:16500.

Yano, S., Kanaya, M., and Takafuji, A. 2003. Genetic basis of color variation in leaf scars induced by the Kanzawa spider mite. Entomol Exp. Appl. 106:37-44.

Zarate, S. I., Kempema, L. A., and Walling, L. L. 2007. Silverleaf whitefly induces salicylic acid defenses and suppresses effectual jasmonic acid defenses. Plant Physiol. 143:866-75.

Zhang, P. J., Zheng, S. J., van Loon, J. J. A., Boland, W., David, A., Mumm, R., and Dicke, M. 2009. Whiteflies interfere with indirect plant defense against spider mites in lima bean. Proc. Natl. Acad. Sci. U.S.A. 106:21202-7.

Zhao, C., Escalante, L. N., Chen, H., Benatti, T. R., Qu, J., Chellapilla, S., Waterhouse, R. M., Wheeler, D., Andersson, M. N., Bao, R., Batterton, M., Behura, S. K., Blankenburg, K. P., Caragea, D., Carolan, J. C., Coyle, M., El-Bouhssini, M., Francisco, L., Friedrich, M., Gill, N., Grace, T., Grimmelikhuijzen, C. J. P., Han, Y., Hauser, F., Herndon, N., Holder, M., Ioannidis, P., Jackson, L., Javaid, M., Jhangiani, S. N., Johnson, A. J., Kalra, D., Korchina, V., Kovar, C. L., Lara, F., Lee, S. L., Liu, X. Löfstedt, C., Mata, R., Mathew, T., Muzny, D. M., Nagar, S., Nazareth, L. V., Okwuonu, G., Ongeri, F., Perales, L., Peterson, B. F., Pu, L.-L., Robertson, H. M., Schemerhorn, B. J., Scherer, S. E., Shreve, J. T., Simmons, D., Subramanyam, S., Thornton, R. L., Xue, K., Weissenberger, G. M., Williams, C. E., Worley, K. C., Zhu, D., Zhu, Y., Harris, M. O., Shukle, R. H., Werren, J. H., Zdobnov, E. M., Chen, M.-S., Brown, S. J., Stuart, J. J., and Richards, S. 2015. A massive expansion of effector genes underlies gall-formation in the wheat pest Mayetiola destructor. Curr. Biol. 25:613-20.

Zheng, S. J., van Dijk, J. P., Bruinsma, M., and Dicke, M. 2007. Sensitivity and speed of induced defense of cabbage (Brassica oleracea L.): Dynamics of BoLOX expression patterns during insect and pathogen attack. Mol. Plant-Microbe Interact. 20:1332-45.

Zhurov, V., Navarro, M., Bruinsma, K. A., Arbona, V., Santamaria, M. E., Cazaux, M., Wybouw, N., Osborne, E. J., Ens, C., Rioja, C., Vermeirssen, V., Rubio-Somoza, I., Krishna, P., Diaz, I., Schmid, M., Gomez-Cadenas, A., Van de Peer, Y., Grbic, M., Clark, R. M., Van Leeuwen, T., and Grbic, V. 2014. Reciprocal responses in the interaction between Arabidopsis and the cell-content-feeding chelicerate herbivore spider mite. Plant Physiol. 164:384-99. 